\title{
Occupy Wall Street e Los Indignados: uma névoa de insatisfação no século XXI
}

Paulo Roberto Alves Teles

Resumo: We are 99\% (Nós somos 99\%). O slogan presente em inúmeras bandeiras de movimentos sociais ocorridos no início do século XXI tem evidenciado uma marcante insatisfação de segmentos da sociedade em relação a desigualdade. O presente artigo tem como objetivo analisar e discutir os movimentos Occupy Wall Street (EUA) e Los Indignados (15M - Espanha) por entendermos que estes representam de forma sintomática a realidade descrita acima. Após a Crise de 2008, o processo de precarização de direitos constitucionalmente garantidos se intensificou e devido a isso, inúmeras manifestações e movimentos sociais se sublevaram contra as políticas de austeridade e a exclusão sistemática dos indivíduos na participação política dos seus respectivos países. Indignados e desesperançosos, milhares de cidadãos saíram às ruas para reivindicar direitos e transformações sociopolíticas dos seus países.

Palavras-chave: Movimentos sociais, desigualdade, ativismo político.

\section{Occupy Wall Street e Los Indignados: a fog of unsatisfaction in the $21^{\text {st }}$ century}

\begin{abstract}
We are 99\%. The slogan present in numerous flags of social movements occurred at the beginning of the 21st century has evidenced a marked dissatisfaction among segments of society in relation to inequality. This article aims to analyze and discuss the movements Occupy Wall Street (USA) and Los Indignados (15M - Spain) because we understand that they represent symptomatically the reality described above. After the 2008 Crisis, the process of precariousness of constitutionally guaranteed rights intensified and due to this, numerous demonstrations and social movements revolted against the policies of austerity and the systematic exclusion of individuals in the political participation of their respective countries. Outraged and hopeless, thousands of citizens took to the streets to demand the rights and socio-political transformations of their countries.
\end{abstract}

Keywords: Social movements, inequality, political activism.

Artigo recebido em 03/01/2017 e aprovado em 28/02/2017.

\section{Introdução:}

Muitas vezes incompreendidos ou recebidos como surpresa, os movimentos sociais podem ser interpretados como promessas e até mesmo profetas da Modernidade ${ }^{\mathrm{II}}$. Entendida como um período claramente marcado pelos impactos da 
Revolução Industrial e do processo de racionalização do pensamento humano, a Modernidade tem sido alvo de questionamentos constantes, especialmente, pelas sequelas negativas que ela trouxe a inúmeras camadas sociais. O objetivo desse artigo, consiste numa abordagem sobre as manifestações surgidas nos EUA e na Espanha após a crise de 2008 e pela atual condição socioeconômica atual ${ }^{\mathrm{III}}$, tendo como alvo específico os movimentos Occupy Wall Street e Los Indignados.

Diante dos impactos socioeconômicos marcados por uma profunda desigualdade e concentração de riquezas, não é de se estranhar que os excluídos desse processo tenham construído mecanismos de mobilização e organização contra as sequelas que os afetaram. Portanto, os movimentos assim surgidos e as promessas advindas dos mesmos, ainda que tenham sido e de certo modo ainda o são demasiadamente amplas, reivindicam transformações que circulam em torno da emancipação dessas categorias sociais perante os malefícios trazidos pelos novos processos produtivos.

Assim, ao ser considerado profeta, os movimentos sociais podem ser vistos como um termômetro de algo que está anunciado e denunciado a acontecer, mesmo que ainda não o tenha de fato. Portanto, é preciso compreender os movimentos sociais como sujeitos políticos responsáveis por denunciar os problemas da Modernidade e ao mesmo tempo como ferramentas necessárias para questionar a própria realidade em si. Além disso, é preciso entende-los também como criadores ativos de repertórios e ferramentas de lutas. Se outrora a greve teria sido uma forma de reivindicação, hoje a ocupação de espaços públicos por manifestações e movimentos antiglobalizantes se apresenta como principal mecanismo de atuação política.

\section{Ações coletivas e Movimentos sociais: uma breve abordagem teórica}

A construção de teorias que visavam compreender os grandes movimentos sociais do século XIX e XX foram assentadas em princípios epistemológicos advindos das concepções marxistas e weberianas. No entanto, nem Marx ou Weber estabeleceram teorias que tinham como propósito específico a abordagem do movimento social em si. Enquanto que o primeiro teorizou sobre o conflito sociopolítico e a sua interpretação sobre as origens e razões do mesmo, o segundo abordou sobre a ação social e as suas motivações.

Nesse sentido, as teorias construídas pelos autores citados acima abordaram estruturas ou modelos socioeconômicos e comportamentais específicos e surgidos numa Europa marcada pelo advento da Industrialização ${ }^{\mathrm{IV}}$.

Outro problemática a ser destacada reside na compreensão sobre as Ações coletivas. Se tomarmos como ponto de partida a interpretação marxista ${ }^{\mathrm{V}}$, é praticamente impossível discutir as teorias da ação coletiva sem problematizar a desigualdade econômica, principal elemento mobilizador das massas. Uma vez entendida dessa maneira, compreende-se as ações coletivas como elementos construídos a partir de interesses compartilhados e ainda, uma consciência comum. Karl Marx (2012) considerava que as ações coletivas necessitavam de três pontos fundamentais: interesses compartilhados, organização e consciência comum, sendo o descontentamento o ponto crucial de desencantamento necessário para que as ações coletivas se tornassem de fato, movimentos sociais.

No caso Weberiano $(2012)^{\mathrm{VI}}$, a ação coletiva não pode ser entendida sem a compreensão dos atores sociais. De acordo com Weber (2012) 
“(...) Social actions, like other forms of action, may be classified in the following four types according to its mode orientation: (I) in terms of rational orientation to a system of discrete individual ends (zwecrational), that is, through expectations as to behaviour of objects in the external situtation and of other human individuals, making use of these expectations as 'conditions' or 'means' for the successuful attainment of the actor's own rationaly chosen ends; (2) in terms of rational orientatiton to na absolute value (wertrational); involving a conscious belief in the absolute value of some ethical, aesthetic, religious, or other formo $\mathrm{f}$ behaviour, entirely for its own sake and independently of any prospects of external success; (3) in terms of affectual orientation, especially emotional, determined by the specific affects and states of feeling of the actor; (4) tradionatilly oriented, through the habituation of long practice (...)"VIII.

Percebe-se assim, que para Weber (2012), as ações coletivas somente podem ser entendidas a partir de elementos e perspectivas que problematizem os indivíduos atuantes nessas ações, isto é, os elementos formativos e afetivos dos indivíduos devem ser problematizados e abordados para a possível compreensão da ação coletiva.

Uma possibilidade de análise, também pode ser encontrada em Sidney Tarrow $(1998)^{\mathrm{VIII}}$. Este aponta que as ações coletivas seriam norteadas por decisões individuais. Nesse sentido, é preciso levar em consideração os limites e incentivos externos que promoveriam a participação de indivíduos em movimentos da sociedade civil (estruturas de oportunidade política), ou sobre o impacto de predisposições psicológicas individuais no envolvimento de organizações sociais e políticas, o que na concepção do autor, seria responsável pela elaboração de círculos de protestos.

Por fim, Charles Tilly (1978) ${ }^{\mathrm{IX}}$ aponta que as ações coletivas são formadas a partir de expectativas de transitoriedade, e isto não significa por si só efemeridade, mas sim dinamismo, ou seja, essas ações se apresentam como elementos permanentes de mudanças e transformações. Para ele, cinco elementos são necessários para a compreensão dessas ações: 1) Grupos sociais envolvidos; 2) população; 3) crenças e valores; 4) eventos em si e 5) ações sócias.

Diante do aspecto de constante mudança, como entender aquilo que ainda não se sedimentou? Uma possibilidade reside na análise conjuntural na qual está imersa a ação coletiva. Contudo, essa análise não pode ser meramente descritiva, é preciso abordá-la de maneira conceitual e compreender que ainda assim, o repertório conceitual também se apresenta de forma transitória, uma vez que, os conceitos tem por natureza um aspecto temporal.

Por isso, é preciso estar atento para que a análise conjuntural não seja influenciada pelos fantasmas do passado, isto é, eventos que ocorreram outrora. Assim, análises reduzidas a comparações com o passado nem sempre possuem a relação devida, muito embora, é preciso atentar que isso não tornará a ação coletiva necessariamente inédita, especialmente pelo movimento social que ela poderá proporcionar, é fundamental levar em consideração a possibilidade de uma continuidade.

Portanto, compreender a ação coletiva e o movimento resultante dela é entendelos como resultados de conflitos entre grupos antagônicos e ainda grupos que estão em disputa, para a partir disso, entender os seus agentes e protagonistas e ao mesmo tempo compreender a dualidade ativista-militante. O que os diferencia?

Abordar as disputas semânticas entre esses conceitos é algo inerente a própria compreensão da Ação coletiva e do movimento social. Uma vez que, o militante está vinculado a condição de ser alguém preparado para atuar e agir em um engajamento prolongado, com um caráter muito mais combativo. Enquanto que, o ativista está 
vinculado à predisposição de fazer algo, ou seja, consistiria num indivíduo que se torna ativo na sociedade e que se mobilizaria por um tempo mais curto, geralmente, durante a ocorrência do elemento responsável pela ignição da Ação coletiva.

Em sua perspectiva, Alain Touraine $(1971)^{\mathrm{X}}$ aborda a questão entre o ator social e o sujeito político. A discussão estabelecida pelo autor apresenta uma análise a partir de conflitos entre elementos sociais e estruturas de poder, que vão além da ideia de centralidade capital x trabalho. Sua abordagem exibe uma compreensão de dominação policêntrica (capital, mídia e Estado).

Nesse sentido, a interpretação do autor tenta se desvincular de uma análise simplesmente empiricista. Para tanto, é necessário uma abordagem mais ampla da sociedade na qual atores sociais, sujeitos políticos e movimentos sociais estariam inseridos. É preciso compreendê-los em sua historicidade. Para isso, é necessário pensar o conflito no cotidiano, de maneira mais intimista, isto é, na vida social e privada. Uma vez que, o conflito social permeia ambos os aspectos.

Se tomarmos como parâmetro, os eventos selecionados por esse artigo, a análise poderia ser realizada desde o processo de desmantelamento dos serviços públicos até a formação de uma nação de indigentes. Processo esse, que não fora exclusivo dos locais onde os movimentos selecionados ocorreram, ao contrário, é uma realidade presente no mundo ocidental. Seja por razões de teor local, ou influências externas, o que se assiste a partir de 2008, é um Ciclo de Indignação Global como apresentou Eduardo Romanos (2016) ao discutir a inter-relação entre os movimentos ocorridos no Egito, na Espanha e nos EUA ${ }^{\mathrm{XI}}$.

\footnotetext{
“(...) Esta confluencia de experiencias remite a un campo global de contienda a tener en cuenta a la hora de analizar procesos específicos de difusión transnacional. Además de las innovaciones específicas aprendidas a partir de una movilización en concreto, los activistas se ven influenciados por todo un imaginario global de discursos y prácticas contenciosas. En cualquier caso, la referencia a otras experiencias de horizontalismo nos ayuda a entender algunas diferencias entre los procesos deliberativos en Zuccotti Park y las plazas españolas $(\ldots)^{\mathrm{XII}}$,.
}

O que é comum entre esses eventos como ponto-chave de indignação? Situações de desigualdade.

\section{A Desigualdade como princípio}

Em sua incômoda obra, $O$ Mal ronda a Terra: Um tratado sobre as insatisfações do presente (2011), Tony Judt aponta que os últimos 30 anos tem sido marcados por um processo de desmantelamento das conquistas obtidas no pós-guerra. Em sua visão, a desconstrução do Estado de Bem-Estar Social, tanto político-econômica, quanto cultural foi caracterizada por processo sistemático de perda de confiança na relação entre indivíduos e entre este e o Estado. Em suas palavras “(...) Quanto mais igualitária for uma sociedade, maior a confiança. E não se trata apenas de renda: onde têm a vida e expectativas semelhantes, as pessoas costumam compartilhar o que podemos chamar de "perspectiva moral" (...)"XIII.

É fundamental destacar, que não se trata de uma diferença entre categorias sociais, mas sim num constante aumento da desigualdade entre as mesmas, sentido mais intensamente no espaço urbano. Esse processo também esteve relacionado a uma 
precarização dos serviços oferecidos pelo Estado e os seus custos tornaram a sua manutenção cada vez mais onerosa para os cofres públicos. Diante disso, a geração herdeira dos babyboomers (geração de indivíduos nascida no pós-guerra e principal beneficiária do Welfare State), especialmente por não ter vivido os anos de privação existentes ao longo da Crise de 29 ou até mesmo da Segunda Guerra experimentado pelos seus pais, pôs em xeque a manutenção desse modelo de governança, questionando-o em sua eficiência e viabilidade. Esses jovens adultos dos anos 1960 mergulharam cada vez mais em um sentimento individualista que, passou a fazer sentido diante das crises econômicas assistidas ao longo dos anos 1970.

\footnotetext{
“(...) Como advertem Rocard e colaboradores, a principal vítima do aprofundamento da desigualdade será a democracia, já que a parafernália cada vez mais escassa, rara e inacessível da sobrevivência e da vida aceitável se torna objeto de rivalidades cruelmente sangrentas (e talvez de guerras) entre os bem-providos e os necessitados e abandonados (...)"XIV
}

Sustentados por essa geração, governos, cuja ideologia era norteada pelo pensamento neoliberal, adotaram medidas político-econômicas que delegavam a iniciativa privada, funções antes pertencentes ao Estado. Essas últimas, movidas pelo seu objetivo de lucratividade, e cientes de que em caso de má gestão, os governos utilizariam recursos públicos para ajuda-las, sentiram-se seguras para diminuir a qualidade dos serviços em prol de uma maior redução dos custos. As demandas oferecidas não eram suficientes aos herdeiros dos babyboomers, os quais começaram a enxergar o Estado como obstáculo para a sua expressão e liberdade individual, o discurso por menos Governo e mais Liberdade ganha força no cenário cultural e por conseguinte, político-econômico.

Essa prática, assistida especialmente ao longo dos anos 1980-1990, foi caracterizada por uma intensa precarização dos serviços antes públicos. A população urbana, cada vez mais aglutinada em um espaço com péssima infraestrutura e baixos investimentos nesses mesmos serviços, acumulou ao longo desses últimos anos um sentimento de mal-estar generalizado também percebido por David Harvey (2015). Recentemente, Harvey (2015) afirmou que vivemos sob um mal estar urbano generalizado, uma vez que, em suas palavras, "Nós estamos construindo cidades para investir, não para viver".

Portanto, percebe-se um processo de abdicação dos compromissos morais atribuídos ao Estado. O governo se isenta da responsabilidade e a transfere para uma iniciativa privada desprovida de compromissos morais para com a sociedade e que vislumbra somente mecanismos mais eficazes de garantir a sua lucratividade. Não há então razões para que o indivíduo se sinta representado pelo sistema político, uma vez que, o mesmo está vinculado aos compromissos econômicos com as empresas que o financiaram. Há aqui uma ruptura clara e evidente entre Governo e sociedade civil. O resultado disso: uma sociedade debilitada e não-representada.

“(...) Um governo que reconhece sua relutância em assumir tais responsabilidades, preferindo passa-las ao setor privado e deixa-las ao sabor dos caprichos do mercado, pode contribuir para o aumento de sua eficácia ou não. Mas estará abandonando as atribuições principais do Estado Moderno $(\ldots)^{\text {"XV }}$. 
Não são recentes os trabalhos que discutiram os efeitos da globalização sobre os indivíduos. Se a tomarmos como reflexo da Modernidade, encontraremos em Marshall Berman (1986) uma profunda e incômoda análise sobre os impactos da mesma no mundo contemporâneo. Berman (1986), ao retomar a frase emblemática de Marx (1999) "Tudo que é sólido se desmancha no ar", acreditava que o homem teria, através das transformações promovidas ao longo da Modernidade, construído um mundo no qual ele teria sido capaz de dominar a natureza.

As inquietações em relação a esse novo mundo também encontram reflexo na obra de Tony Judt (2011), o qual tece profundas críticas ao mundo contemporâneo que ele próprio descreveu como materialista e egoísta. De acordo com Judt (2011), esse mundo fora forjado a partir dos anos 80 e teria sido responsável pela construção de um comportamento obsessivo pela acumulação de riqueza, pelo culto a privatização e pela crescente desigualdade entre ricos e pobres. $\mathrm{O}$ autor considera que as transformações sociais e econômicas assistidas nos últimos trinta anos foram responsáveis por um processo de precarização dos serviços prestados a sociedade e ainda, por uma constante sensação de desesperança em relação ao futuro. Em suas palavras

“(...) Razões para se estar revoltado não faltam: desigualdades crescentes em termos de oportunidades e riqueza; injustiças de classe e casta; exploração econômica interna e internacional; corrupção, dinheiro e privilégios obstruindo as artérias da democracia (...)"XVI .

Portanto, Judt (2011) nos apresenta em suas reflexões um novo mundo, o qual fora forjado sob as égides da insegurança e desigualdade. Mundo este que, cada vez mais, aspectos correspondentes aos direitos essenciais garantidos aos indivíduos pertencentes a sociedades democráticas estão cada vez mais dilapidados. Contudo, no alvorecer do século XXI, esses indivíduos despertaram e através de sua indignação tomaram as ruas para reivindicar os seus direitos já então precarizados.

Nesse sentido, o processo de fortalecimento da individualização defendida por economistas do livre-mercado e por uma geração de pessoas que o legitimaram, ao invés de fortalecer os segmentos e as instituições democráticas, apresentaram o efeito reverso. Pois, o que se percebeu nos últimos anos foi o fortalecimento dos mecanismos de vigilância e proteção a instituições privadas realizadas pelo Governo, isto é, o desmantelamento dos serviços públicos em benefício da iniciativa privada, além de segregar a sociedade, contribuíram para o fortalecimento de práticas autoritárias, um bom exemplo, corresponde aos mecanismos de controle e dispersão utilizados pelas forças públicas contra as manifestações de rua em prol de direitos civis. Um outro bom exemplo, reside na redução da participação dos indivíduos no processo de eleições de representantes para o Parlamento europeu, o que evidencia uma gradativa crise no sistema político democrático movida pela descrença dos cidadãos no próprio modelo que elege os seus representantes.

Portanto, essa descrença generalizada em relação ao sistema político e o sentimento de falta de representatividade com o governo e os partidos políticos que o compõe teriam sido o veículo motor necessário para no final dos anos 2000 , cidadãos comuns, herdeiros desse processo histórico de desmantelamento do Estado fornecedor de direitos civis e sociais, transbordassem o seu mal-estar e saíssem às ruas.

“(...) Em nossa vida política, assim como na econômica, fomos transformados em consumidores: escolhemos dentre uma ampla gama de 
objetivos competitivos, mas encontramos dificuldade em imaginar maneiras ou razões para combiná-los num conjunto coerente. Precisamos ir além. $(\ldots)^{n \times \mathrm{XVII}}$.

Nesse sentido, as manifestações surgidas nesse novo século buscariam, entre outras demandas, defender ou ao menos reconstruir preceitos democráticos, como o acesso a direitos sociais constitucionalmente garantidos, fragilizados em prol de ganhos econômicos privados.

Os movimentos de rua seriam correspondentes à pressões sociais em prol da defesa da democracia, ameaçada pelos malefícios de uma globalização excludente, ou seja, são manifestações de estranhamento perante o cenário atual. Para Slavoj Žižek (2012), a ocupação de espaços públicos corresponderiam a retomada de posicionamentos políticos até então adormecidos. Estes teriam se iniciado a partir de movimentos alter-globalizantes surgidos no final dos anos 1990 em Seattle, que ganharam corpo com a criação de Fóruns Sociais Mundiais. No entanto, é necessário destacar que diferentemente desses movimentos alter-globalizantes, isto é, movimentos que buscam apresentar propostas alternativas à globalização, como ressalta Maria da Glória Gohn

“(...) O Occupy não tem alvo fixo, enquanto os manifestantes de Seattle elegeram as reuniões de cúpula internacional (OMC, FMI, etc.). E Seattle aconteceu em momento de alta e boom do capitalismo ocidental; Wall Street não, aconteceu durante um momento de profunda crise. (...)"XVIII

Portanto, é interessante destacar que esses movimentos pertencem a um período de estranhamento ou inquietude assistido no alvorecer do século XXI como ressaltou Alain Touraine (2002). Dessa maneira, as manifestações surgidas seriam um mecanismo de pressão social perante as autoridades e lideranças políticas, especialmente por essas, sejam elas indivíduos, sindicatos ou partidos, não inspirarem mais confiança entre esses manifestantes.

Como ressaltou Žižek “(...) os manifestantes perceberam que por um longo tempo permitiram que seus compromissos políticos também fossem terceirizados $-e$ querem-nos de volta (...)"XIX . A ideia de inquietação também fora ressaltada pelo historiador Robert Darnton (2011). Para ele, esses movimentos são frutos da inquietude das pessoas perante os problemas contemporâneos, Darton (2011) avalia que o movimento Occupy Wall Street teria sido fruto de uma inquietação social, a qual teria alcançado segmentos dos mais diversos setores sociais, incluindo a classe média americana, afetada pela crise de 2008. Em suas palavras “(...) Os protestos devem ser levados a sério. Não como uma ameaça de qualquer tipo de agitação revolucionária, mas como um sinal de inquietação profunda (...)"xx.

Francisco Carlos Teixeira da Silva (2013) também se dedicou a analisar esses movimentos. Utilizando-se de métodos histórico comparativos, o autor destacou alguns pontos em comum entre os movimentos ocorridos nos EUA, Europa e Mundo Árabe. Silva (2013) destaca que os manifestantes presentes nesse movimento pertencem, em larga medida, a uma faixa etária inferior aos 21 anos e muitas vezes integram grupos étnicos marginalizados. Outro aspecto marcante incide na falta de preparo das forças policiais no tratamento desses movimentos, que muitas vezes resultou na brutal violência contra os manifestantes. 
Dessa maneira, existe aqui, ainda que de forma inicial, um perfil de manifestante: Jovem, marginalizado e sem perspectiva em pleno mundo contemporâneo. Silva (2013) ainda aponta que nos casos Los Indignados (Espanha) e Occupy Wall Street (EUA) há uma enorme proximidade no que se refere "(...) um sentido de inutilidade e de ausência de perspectivas, de perda de esperanças diretamente relacionados com as políticas públicas incapazes de criar empregos (...)"xxI.

Em suas discussões sobre os movimentos surgidos no século XXI, Manuel Castells (2013) retoma os princípios presentes também discutidos por Jünger Habermas (2012) ao enfatizar a capacidade de comunicação entre os participantes e simpatizantes dos movimentos. A concepção do agir comunicativo é fundamental para o esclarecimento de seus componentes, os quais são capazes de destituir a mídia tradicional televisiva como única e exclusiva narradora dos eventos ocorridos naquele período.

Além disso, a perda de credibilidade por parte desse jornalismo é resultado da capacidade comunicativa proporcionada pela internet. Portanto, a construção de novas mentalidades através desse agir comunicativo possibilitou nesses movimentos propostas, cujo cerne é reinventar a Democracia. Não se trata de destruir o Capitalismo, mas sim repensá-lo, reestruturar toda a Revolução Industrial se necessário. Visto que, as organizações político-partidárias e as suas respectivas instituições cederam aos interesses dos mercados financeiros e de grupos plutocratas dominantes, e exatamente por isso, perderam não só a credibilidade como também a sua representatividade perante os indivíduos.

Portanto, repensar a Democracia através de uma nova mentalidade é fundamental para a gestação de uma sociedade menos desarmônica. Possivelmente, um sistema político que supere a convalescida Democracia Representativa, uma possibilidade seria a construção de um sistema político mais participativo e transparente, capaz de fortalecer os vínculos de compromisso entre o indivíduo e o Estado e, entre o Governo e a sociedade civil.

A retomada do debate levantado pelo obra "O direito à cidade" de Henry Lefebvre (2001) tem sido destaque nos últimos anos, uma vez que os movimentos e as propostas políticas discutidas no Maio de 68 perderam espaço para uma cultura excessivamente individualista nascida em meados dos anos 70 e que se tornou preponderante nos últimos anos. Essa é a constatação de David Harvey (2012), que aponta no processo de exclusão social desencadeado por políticas econômicas que beneficiaram setores especulativos e o mercado financeiro o epicentro para as problemáticas sociais dos nossos dias: “(...) vivemos num mundo onde os direitos de propriedade privada e a taxa de lucro se sobrepõem a todas as outras noções de direito (...)"XXII.

Para o autor, a liberdade de construir um processo de urbanização que atendesse às demandas coletivas foi vilipendiada por interesses econômicos protegidos pelas mais diversas instituições políticas, sejam delas democráticas ou não. Dessa maneira, direitos sociais como moradia foram postos de lado em prol da especulação imobiliária, o transporte público fora sucateado em benefício da indústria automobilística, a segurança pública substituída pela privativa, dentre outros inúmeros exemplos (educação, saúde, condições de trabalho etc). E como coroação de todo esse processo está a desigualdade que é responsável pela formação de bolsões de pobreza nas mais diversas cidades do mundo. Sejam eles favelas, projects (moradias populares inglesas) ou cités (guetos 
franceses), a razão formadora deles é a mesma, a desigualdade, muitas vezes alimentada, pelo desejo de lucro promovido por Bancos e Agências Financeiras.

A percepção da desigualdade pelos cidadãos residentes nesses espaços urbanos teria sido o elemento de indignação para os primeiros protestos, uma vez estes sendo viralizados (termo designado para o fenômeno de alto compartilhamento de conteúdo nas redes sociais) promoveriam a insurgência de vários outros indivíduos e a exigência por outras e mais diversas bandeiras. O cidadão comum, torna-se ativista e nesse processo de metamorfose ele vai de encontro aos malefícios trazidos por uma globalização excludente:

“(...) Os protestos, em seu conjunto, não são partidários, conduzidos por um grupo ou partido ou mesmo claramente explicitados em uma plataforma. Emergem de uma condição de mal-estar difusa e sistêmica. Por isso mesmo, os protestos são altamente explosivos (....)"XXIII.

É interessante destacar que a crise econômica nascida em 2008 não deve ser vista como única razão motivadora para o despertar do sentimento de indignação. Há de fato um sentimento de estranhamento em curso, que tem provocado o surgimento de movimentos alter ou antiglobalizantes desde os anos 1990 e questionado modelos de vida instituídos pela agenda neoliberal e marcados por profundo comportamento consumista. Esses movimentos tem se organizado desde então a partir de iniciativas como o Fórum Social Mundial e ocupações de espaços públicos.

No entanto, é bem verdade que a crise atual acelerou o processo de entrada de indivíduos, antes indiferentes a esses movimentos, nas manifestações de rua ocorridas pós crise de 2008, como constata Maria da Glória Gohn (2013) "De simpatizantes da causa, os sujeitos que atendem às chamadas para os atos de protesto poderão se tornar ativistas de um novo movimento social". Especialmente quando estes contrastavam as suas precárias condições de vida diante dos benefícios e privilégios garantidos a membros do governo ou de outros setores da sociedade através de práticas corruptas ou minimamente questionáveis.

\section{A Indignação sai às ruas}

Surgidos no mesmo ano (2011), os movimentos de rua, Occupy Wall Street e Los Indignados corresponderam a formas de manifestações diferentes ocorridas como resposta aos desdobramentos da crise de 2008. No entanto, antes de analisarmos algumas características desses movimentos é interessante abordar o conceito de Movimento Social que norteará, a princípio, o nosso trabalho:

\footnotetext{
“(...) nós os vemos como ações sociais coletivas de caráter sociopolítico e cultural que viabilizam distintas formas da população se organizar e expressar suas demandas. $\mathrm{Na}$ ação concreta, essas formas adotam diferentes estratégias que variam da simples denúncia, passando pela pressão direta (mobilizações, marchas, concentrações, passeatas, distúrbios à ordem constituída, atos de desobediência civil, negociações etc.), até as pressões indiretas. $\mathrm{Na}$ atualidade, os principais movimentos sociais, locais, regionais, nacionais e internacionais, e utilizam-se muito dos novos meios de comunicação e informação, como a internet (...)"XXIV .
} 
Dito isto, o que se percebe de imediato é que, o alvorecer do século XXI proporcionou novos mecanismos de organização sociopolítica e através deles, novas ferramentas e estratégias de mobilização. A comunicação móvel, associada as redes sociais, potencializaram as manifestações e através desses recursos, proporcionaram o surgimento de um novo método de ativismo político.

Insatisfeitos com os prejuízos trazidos pela Crise de 2008, milhares de indivíduos saíram às ruas nos EUA, especialmente em Nova York, contra o mercado financeiro, cujo alvo específico fora Wall Street. O centro do financeiro mundial se tornou, para essas pessoas, o símbolo maior de práticas econômicas desleais que conduziram a sociedade americana ao colapso. Movidos por sua indignação, esses indivíduos ocuparam Zuccoti Park e questionaram a autoridade e o comportamento daquilo que David Harvey (2012) denominou Partido Wall Street, grupo financeiro que domina o cenário político econômico americano, quiçá mundial, a várias décadas. Para Harvey

\begin{abstract}
“(...) O Partido de Wall Street controlou os Estados Unidos sem dificuldade por tempo demais. Dominou completamente (em oposição a parcialmente) as políticas dos presidentes por pelo menos quatro décadas (para não dizer mais), independentemente de presidentes individuais terem ou não sido seus agentes por vontade própria. Corrompeu legalmente o Congresso por meio da dependência covarde dos políticos de ambos os partidos em relação ao poder do seu dinheiro e ao acesso à mídia comercial que controla (...)"XXv .
\end{abstract}

Nesse sentido, sob o slogan "We are 99\%" (Nós somos 99\%) ${ }^{\mathrm{XXVI}}$, parte da sociedade americana se subleva contra o seu atual modelo econômico e exige por parte das suas autoridades políticas, mudanças imediatas em suas práticas econômicas e as suas ações políticas. Apesar de difuso, o movimento destoa de manifestações antiglobalizantes que o precederam, elemento o qual discutiremos mais adiante.

Do outro lado do Atlântico, mas também sob os efeitos da Crise de 2008, espanhóis também se sublevaram no mesmo ano que os americanos. Contudo, sua luta foi muito mais além do que uma contestação econômica, entre os Indignados XXVII ou movimento 15 de Maio surgiu, após a convocatória de uma plataforma civil e digital ¡Democracia real Ya! (Democracia Real Já) ${ }^{\mathrm{XXVIII}}$. Responsável por uma série de reuniões e ocupações públicas, além de propostas políticas e questionamentos contra o programa econômico do país, o Movimento 15-M possibilitou o nascimento do partido político Podemos. Composto por jovens plugados (usuários de redes sociais), o movimento faz duras críticas a tudo aquilo que representa o establishment espanhol, isto é, parlamento, partidos, sindicatos, empresas, Igreja Católica e monarquia.

Apesar da sua maior complexidade e profundidade quando comparado ao movimento Occupy Wall Street, existem elementos que nos chamam a atenção. 1) Ambos iniciaram suas atuações no mesmo período, Los Indignados (maio de 2011) e Occupy Wall Street (setembro de 2011); 2) Os dois possuíram espaços físicos em comum para as ações de seus manifestantes, Puerta de Sol (Madri), Praça Catalunha (Barcelona) e Zuccoti Park (Nova York). No caso americano, temos um aspecto profundamente interessante, uma vez que Zuccoti Park, formalmente chamado de Liberty Plaza Park não é um espaço público em si, ele corresponde a um espaço privado de uso público mantido pela empresa Brookiefield Office Properties Inc. Com o início do movimento Occupy Wall Street, essa praça foi reivindicada como espaço público pelos manifestantes; 3) Os movimentos apresentaram como principal veículo de 
mobilização, a comunicação móvel realizada por aparelhos celulares e redes sociais; 4) Os membros desses movimentos são compostos em sua grande maioria por jovens; 5) Por fim, os movimentos não possuíram uma liderança clara ou pauta específica.

Um outro elemento a ser apontado reside na inter-relação desses movimentos. Eduardo Romanos (2016) evidencia que a atuação de ativistas e imigrantes espanhóis foi fundamental para auxiliar a logística de atuação do movimento Occupy Wall Street, especialmente no que se refere a aspectos de abastecimento, alojamento e divulgação dos atos promovidos pelos participantes. Nesse sentido, a troca de experiências e os estímulos proporcionados a ambos os movimentos evidenciam uma inter-relação necessária e fundamental para as ações coletivas realizadas ao longo desse processo.

$\mathrm{O}$ autor apresenta três elementos fundamentais presentes nesses movimentos sociais e suas respectivas ações coletivas: 1) a ideia de injustiça, responsável pela indignação coletiva; 2) o componente agencial, isto é, a concepção de que é possível mudar a sua realidade a partir de ações coletivas; 3) o elemento identitário, o autoreconhecimento entre os membros integrantes seja entre suas angústias, como se manifestou no Occupy Wall Street, ou em suas propostas de transformação políticas, apresentadas sobretudo no movimento Los Indignados ou 15M. “(...) Una de las novedades del $15 \mathrm{M}$ residiria en colocar en el centro del espacio público la experimentación con un nuevo modelo de democracia $(. . .)^{\mathrm{XXIX}}$.

Dessa forma, percebe-se que esses movimentos apresentaram um novo perfil de manifestante e também uma nova forma de atuação política, a qual cobra das instituições medidas que solucionem problemáticas estruturais do mundo contemporâneo, além de questionar políticas econômicas de austeridade apresentadas como resposta para a Crise de 2008. Esse indivíduo, antes cidadão comum, agora ativista, tem o poder, via celular de registro do imediato e através disso, de mobilizar milhares e em alguns casos, milhões de pessoas para pressionar as autoridades e instituições públicas em prol da preservação dos seus direitos, ou até, como no caso espanhol questionar toda a estrutura política e a sua respectiva representatividade.

\section{A democracia posta em xeque}

Os malefícios trazidos pela desigualdade exacerbada não afetaram apenas questões de ordem socioeconômica. As instituições político-partidárias edificadas e sedimentadas no mundo ocidental a partir do século XIX também estariam sob ameaça. Especialmente os direitos sociais constitucionalmente adquiridos no pós segunda guerra.

\footnotetext{
“(...) a alergia ao governo que o cidadão decepcionado está sofrendo confunde e questiona os conceitos fundamentais da filosofia política moderna; ela se espalha dos governos e partidos para o Estado e suas instituições, até chegar a seu estágio final, ao qual nós já chegamos: uma alergia à própria democracia. Vemos seus sinais, desde o consenso quanto ao neoimperialismo de Putin até os sucessos de Viktor Orbán ou Erdoğan (...) "XXX.
}

Os elementos fundamentais que justificavam a existência de um Estado Democrático se extinguiram e em seu lugar o que restou foi uma melancólica e silenciosa solidão de indivíduos que se veem cada vez mais pessimistas quanto a sua capacidade individual de transformação política das instituições. O partido e até mesmo 


\section{PAULO ROBERTO ALVES TELES}

o próprio Estado Democrático perdeu o seu sentido e em seu lugar foi posto a necessidade de manutenção do seu vínculo empregatício necessário para o pagamento de sua hipoteca.

Um dos elementos causadores desse efeito reside nas problemáticas trazidas pela globalização, a qual reduziu sensivelmente a capacidade do Estado de transformar a vida dos seus cidadãos, o que contribuiu para o aumento da descrença desses em relação ao Estado, obviamente, que os sucessivos escândalos de corrupção não podem ser desconsiderados como elementos causadores de desesperança.

O que está posto em xeque pelos grupos selecionados é a própria capacidade do Estado representar os interesses e desejos da comunidade. O Estado e as suas instituições mais básicas já não refletem a sociedade que o alicerça, mas sim, agentes financeiros e especulativos, investidores e bancos que agiram e tem agido de maneira eticamente questionável.

O cidadão não entende porque a instituição Polícia age para retirá-lo de sua casa após a execução de uma hipoteca, quando em seu entendimento essa mesma instituição deveria protege-lo da arbitrariedade cometida pelo Banco responsável pela execução. $\mathrm{O}$ paciente não entende porque o Governo permite que planos de saúde e empresas farmacêuticas atuem como agentes especulativos capazes de tornar o acesso aos cuidados médicos uma verdadeira Odisseia contemporânea. $O$ estudante não compreende como a instituição Justiça não o protege dos juros abusivos que tornam a sua dívida acumulada pelo crédito estudantil praticamente perpétua, dívida essa gerada para que ele tivesse acesso a um direito supostamente garantido pela Constituição: $O$ direito a Educação.

Os serviços básicos que, supostamente deveriam ser prestados a sociedade pelo Estado, tornaram-se elementos de barganha por grandes conglomerados empresariais e a partir disso, a lógica de consumo diluiu os elementos básicos que nos integravam enquanto comunidade. Assim, o consumismo passa a ser tratado como elemento responsável por desarticular os preceitos mais básicos e fundamentais que deveriam sedimentar e instituir a ideia de viver em comunidade. A Democracia, antes sustentada sobre esse princípio, também entra em xeque.

Ainda assim, uma vez a Democracia posta em xeque, é possível que o termo cidadão tenha sentido? Ou chegamos ao ponto de nos tornarmos meros consumidores, antes de produtos e serviços mercadológicos e agora de direitos outrora fornecidos pelo Estado? São questionamentos que merecem atenção, especialmente, quando se relaciona com as dificuldades em obter trabalho que, nesse sentido, torna-se uma das últimas trincheiras a ser garantidas pelo indivíduo, uma vez que o salário obtido por ele pode dividir os cidadãos entre miseráveis e sobreviventes.

Assim, o ambiente de trabalho se torna um espaço de tamanha disputa e desconfiança que esses sentimentos facilmente transbordam e se ramificam a ponto de ser direcionados a imigrantes e outros grupos considerados minoritários. A exclusão de indivíduos de seus direitos fundamentais torna a crise atual um elemento de desestruturação das instituições pré-estabelecidas e do sistema político democrático. Portanto, a crise estabelecida criou uma espécie de animosidade e indiferença perante os excluídos de modo que, eles não integram sequer o debate público sobre o combate a crise.

Não é de se estranhar o retorno de discursos falaciosos que impulsionaram a candidatura de figuras políticas carismáticas “(...) Tempos de desesperança são repletos de tumbas de profetas desonestos e falsos salvadores (...)"XxxI. A soma desses 
sentimentos pode ser percebida na explosão de sucessivas manifestações sociais contemporâneas, especialmente as que foram selecionadas por esse artigo.

\begin{abstract}
“(...) Essas manifestações, inclino-me a dizer, são casos de 'solidariedade explosiva': por um instante as pessoas suspendem as diferenças de seus interesses e de suas preferências a fim de liberar a energia acumulada pelo grande número de manifestantes e de maneira tão impressionante (e esperançosamente efetiva). (...)"XXXII.
\end{abstract}

Mesmo esperançosa, é preciso de cautela e não reduzir esses manifestantes a grandes seguimentos revolucionários capazes de transformar o sistema, especialmente, porque muito possivelmente eles não o são, mesmo sendo composto muitas vezes por indivíduos marginalizados e excluídos pelo sistema socioeconômico que se cristalizou nas últimas décadas.

É necessário ressaltar que as manifestações coletivas e as insatisfações generalizadas não criam obrigatoriamente redes de solidariedade. O que a manifestação ou distúrbio revela é, ainda que de maneira difusa e abafada, o grito de existência desses indivíduos perante às instituições que o governam, partidos e sistemas políticos incluso.

É inadmissível para os rebelados perceber que, por alguma razão ainda não compreendida por eles, ter sido excluído do sistema econômico vigente, também o excluiu dos processos políticos que atuam sobre as suas vidas “(...) As pessoas não escolhem um governo que porá o mercado sob o seu controle; em vez disso, o mercado condiciona o governo, de todos os modos, a pôr as pessoas sob o seu controle (...)"XxxIII. Portanto, ao transformar o indivíduo-cidadão em indivíduo-consumidor, a realidade vigente marcada predominantemente pelo consumo o pressiona a se tornar um elemento quase passivo e inerte diante das transformações políticas que afetam a sua vida e a sua realidade. Dito isto, a representatividade política é posta cada vez mais em descrédito, de modo que, não é a crença que garante a eleição do candidato, mas sim a descrença em seu opositor. Por isso, a névoa a qual estão imersos movimentos ou manifestações como Occupy Wall Street e Los Indignados não se desfez e ainda está distante de se desfazer.

\title{
VI. Considerações finais
}

Os primeiros anos do século XXI foram caracterizados por eventos que puseram em xeque modelos e aspectos socioeconômicos estabelecidos até então. O Estado e as suas instituições, a atuação econômica exercida pela iniciativa privada e o temor perante a constante ameaça de perda dos direitos adquiridos a muito custo ao longo do século $\mathrm{XX}$, tornaram-se elementos motivadores para distúrbios ocorridos em inúmeras regiões do Globo.

Somado aos problemas levantados e discutidos acima, um profundo sentimento de estranhamento também se fez presente nesses primeiros anos e se materializou através de ações coletivas produtoras de movimentos sociais extremamente interessantes, seja pelas suas formas de atuação, como também pelas características de seus integrantes e propostas.

Sintomáticos e ainda em curso, movimentos como o Occupy Wall Street e Los Indignados, também conhecido como $15 \mathrm{M}$, apresentaram elementos que os aproximam e também aspectos extremamente particulares atrelados as suas próprias características e contextos locais. Ainda assim, é inegável a sua inter-relação seja na contribuição e na 
organização de suas ações, como também pelas influências que suas práticas exerceram entre si.

Insatisfeitos com a sua realidade e temerosos sobre aquilo que o futuro lhes reserva, esses movimentos não somente contestam o mundo que lhes é apresentado como também se propõe a participar da construção de um novo modelo de sociedade e organização econômica pautada em menos desigualdade. Os resultados de suas reivindicações ainda não foram totalmente compreendidos e muito possivelmente estão distantes de sê-lo, ainda assim, a existência em si desses movimentos e suas respectivas ações já são motivos mais do que suficientes para o despertar de estudos específicos que busquem compreende-los, mesmo que suas propostas sejam acusadas de utópicas ou sonhadoras, é preciso relembrar as sábias palavras de Victor Hugo (2013) ${ }^{\text {XXIV }}$ em Os Miseráveis “(...) Não há nada como o sonho para criar o futuro. Utopia hoje, carne e osso amanhã. (...)".

\section{Notas}

I É doutorando em História Comparada pela Universidade Federal do Rio de Janeiro - UFRJ, mestre em Sociologia pela Universidade Federal de Sergipe - UFS e graduado em História pela Universidade Federal de Sergipe onde integra o Grupo de Estudos do Tempo Presente (UFS-CNPq). Atualmente desenvolve pesquisa sobre o ativismo político no século XXI. pauloteles_aju@ hotmail.com;

II Sobre a Modernidade e os seus dilemas ver BERMAN, Marshall; MOISES, Carlos Felipe; IORIATTI, Ana Maria L (tradução). Tudo que é sólido desmancha no ar: A aventura da modernidade. São Paulo: ed. Companhia das Letras, 1986;

III Recentemente a World Institute for Development Economics Research da Universidade das Nações Unidas destacou que o $1 \%$ mais rico de adultos detinha $40 \%$ dos bens globais em 2000, e ainda que, os $10 \%$ mais ricos concentravam um total de $85 \%$ da riqueza global. (BAUMAN, p.9, 2015)

IV Ver SOMBART, Werner. Socialism and social movement in the 19th century. New York. ed. Createspace Pub, 2015;

V Ver MARX, Karl. A Luta de classes na França (1848-1850). São Paulo, Boitempo, 2012;

VI Ver WEBER, Max. The theory of social and economic organization. Eastford (EUA), ed. Martino Fine Books, 2012;

VII “(...) As ações sociais, como outras formas de ação, podem ser classificadas nos quatro tipos seguintes de acordo com sua orientação modal: (I) em termos de orientação racional a um sistema de fins individuais discretos (zwecrational), isto é, por meio de expectativas quanto ao comportamento de objetos na situação externa e de outros indivíduos, fazendo uso dessas expectativas como "condições" ou "meios" para a realização com sucesso dos próprios fins racionalmente escolhidos pelo ator; (2) em termos de orientação racional para um valor absoluto (wertracional); Envolvendo uma crença consciente no valor absoluto de algum comportamento moral, estético, religioso ou outro comportamento formal, inteiramente por sua própria causa e independentemente de qualquer perspectiva de sucesso externo; (3) em termos de orientação afetiva, especialmente emocional, determinada pelos afetos específicos e estados de sentimento do ator; (4) orientada tradicionalmente, através da habituação da prática longa (...)”. (WEBER, p.115, 2012). Tradução nossa;

VIII Ver TARROW, Sidney. Power in movement: Social Movements and Contentious Politics. Cambridge: Cambridge University Press, 1998;

IX TILLY, Charles. From mobilization to revolution. New York: Macgraw-Hill, 1978.

$\mathrm{X}$ TOURAINE, Alain. The Postindustrial Society: Tomorrow's Social History: classes, conflicts and culture in the Programmed Society. New York: Random House, 1971.

XI Sobre essa temática ver ROMANOS, Eduardo (2016). De Tahrir a Wall Street por la Puerta del Sol: la difusión transnacional de los movimientos sociales en perspectiva comparada. Revista Española de Investigaciones Sociológicas, 154: 103-118. (http://dx.doi.org/10.5477/cis/reis.154.103);

XII “(...) Esta confluência da experiência refere-se a um campo global da disputa a considerar ao analisar processos específicos de divulgação transnacional. Para além das inovações específicas aprendidas a 
partir de uma mobilização, em particular, os ativistas são influenciados por todo um imaginário global de discursos e práticas de litígio. Em qualquer caso, a referência a outras experiências de horizontalidade nos ajuda a compreender alguns diferenças entre os processos deliberativos no Zuccotti Park e nas praças espanholas (...)”. (ROMANOS, p.114, 2016). Tradução nossa;

XIII (JUDT, p.70, 2011);

XIV (BAUMAN, p.10, 2015);

$\mathrm{XV}$ (JUDT, p.114, 2011);

XVI (JUDT, 2011, p.21);

XVII (JUDT, p.130, 2011);

XVIII (GOHN, 2014, p. 130);

XIX ŽIŽEK. Slavoj. O violento silêncio de um novo começo. in: Occupy: movimentos de protesto que tomaram as ruas. São Paulo: ed. Boitempo. 2012.

XX (DARTON, p.1, 2012);

XXI (SILVA, 2013, p.47);

XXII (HARVEY, 2008, p. 1);

XXIII (SILVA, p.28, 2013);

XXIV (GOHN, p.13, 2013);

XXV (HARVEY, p.57, 2012);

XXVI Tradução nossa;

XXVII O termo Indignados tem sido utilizado por uma série de intelectuais, dentre eles David Harvey (2012), Slavoj Žižek (2012) e Maria da Glória Gohn (2013), para se referir aos movimentos de rua ocorridos a partir de 2011, na nossa pesquisa o termo será utilizado para o movimento espanhol;

XXVIII Disponível em <http://www.democraciarealya.es/>. Acesso 17 out 2015;

XXIX "Uma das novidades do $15 \mathrm{M}$ residiria em colocar no centro do espaço público a experimentação como um novo modelo de democracia". (ROMANOS, p.111, 2016). Tradução nossa;

XXX (MAURO. in: BAUMAN, p. 18, 2016);

XXXI (BAUMAN, p.34, 2016);

XXXII (BAUMAN, p.35, 2016);

XXXIII (SARAMAGO. in: BAUMAN, p.59, 2016);

XXXIV Ver HUGO, Victor. Os Miseráveis. Centaur Editions, 2013. Disponível em < http://lelivros.life/book/download-os-miseraveis-victor-hug-em-epub-mobi-e-pdf/> Acesso 15 jan 2017.

\section{Referências bibliográficas}

BAUMAN, Zygmunt. MAURO, Ezio. Babel: Entre a incerteza e a esperança. Rio de Janeiro: ed. Jorge Zahar, 2016;

BAUMAN, Zygmunt. A riqueza de poucos beneficia todos nós? Rio de Janeiro: ed. Jorge Zahar, 2015;

BERMAN, Marshall; MOISES, Carlos Felipe; IORIATTI, Ana Maria L (tradução). Tudo que é sólido desmancha no ar: A aventura da modernidade. São Paulo: ed. Companhia das Letras, 1986;

CASTELLS, Manuel. Redes de Indignação e Esperança: Movimentos sociais na era da internet. Rio de Janeiro. ed. Zahar, 2013;

DARTON, Robert. Ocupe Wall Street não traz "agitação revolucionária. Folha de São Paulo. São Paulo, p. 1, 13 de out. 2011. Disponível em <http://www1.folha.uol.com.br/fsp/mundo/ft1310201110.htm>. Acesso 13 jan. 2015; 
GOHN, Maria da Glória. Manifestações de junho de 2013 no Brasil e Praças dos Indignados no mundo. Petrópolis, RJ: Vozes, 2014;

Movimentos sociais no início do século XXI: antigos e novos atores sociais. Petrópolis, RJ: ed Vozes, 2013;

HABERMAS, Jünger. Teoria do Agir comunicativo V.1. São Paulo: ed. WMF Martins Fontes, 2012;

HARVEY, David. PINHEIRO, Jair (tradutor). O direito à cidade. Disponível em < http://www4.pucsp.br/neils/downloads/neils-revista-29-port/david-harvey.pdf> Acesso 20 fev 2015;

PESCHANSKI, João Alexandre (tradutor). Os rebeldes na rua: O Partido de Wall Street encontra sua nêmesis. in: Occupy: movimentos de protesto que tomaram as ruas. São Paulo Boitempo: Carta Maior, 2012;

HUGO, Victor. Os Miseráveis. Centaur Editions, 2013. Disponível em < http://lelivros.life/book/download-os-miseraveis-victor-hug-em-epub-mobi-e-pdf/> Acesso 15 jan 2017.

JUDT, Tony. O Mal ronda a Terra: Um tratado sobre as insatisfações do presente. ed Objetiva. Rio de Janeiro, 2011;

KOCKA, Jürgen. Comparison and beyond. History and theory 42: 39-44, feb. 2003. Disponível em: <https://pt.scribd.com/doc/223375801/KOCKA-Jurgen-Comparacao-eAlem>. Acesso em 18 abril 2015;

LEFEVBRE, Henry. O direito à cidade. ed Centauro. São Paulo, 2001;

MARX, Karl. A Luta de classes na França (1848-1850). São Paulo, Boitempo, 2012;

ROMANOS, Eduardo (2016). De Tahrir a Wall Street por la Puerta del Sol: la difusión transnacional de los movimientos sociales en perspectiva comparada. Revista $\begin{array}{lllll}\text { Española de Investigaciones } & \text { Sociológicas, } & 154: & 103-118 .\end{array}$ (http://dx.doi.org/10.5477/cis/reis.154.103);

SILVA, Francisco Carlos Teixeira da. Jovens, Indignados e Rebeldes: Uma abordagem comparativa. in: MAYNARD, Dilton Cândido Santos. MAYNARD, Andreza Santos Cruz (org). Visões do Mundo Contemporâneo - Vol 2. São Paulo: LP - Books, 2013;

SOMBART, Werner. Socialism and social movement in the 19th century. New York. ed. Createspace Pub, 2015; 
TARROW, Sidney. Power in movement: Social Movements and Contentious Politics. Cambridge: Cambridge University Press, 1998;

TILLY, Charles. From mobilization to revolution. New York: Macgraw-Hill, 1978; TOURAINE, Alain. O Eixo da Inquietude. Folha de São Paulo. São Paulo, p. 1, 10 de out. 2002; Disponível em <http://www1.folha.uol.com.br/fsp/mais/fs1003200203.htm>. Acesso 10 jan. 2015;

The Postindustrial Society: Tomorrow's Social History: classes, conflicts and culture in the Programmed Society. New York: Random House, 1971;

WEBER, Max. The theory of social and economic organization. Eastford (EUA), ed. Martino Fine Books, 2012;

ŽIŽEK. Slavoj. O violento silêncio de um novo começo. in: Occupy: movimentos de protesto que tomaram as ruas. São Paulo: ed. Boitempo. 2012. 